\title{
Awe Weakens the Desire for Money
}

\author{
Libin Jiang, ${ }^{1}$ Jun Yin, ${ }^{2}$ Dongmei Mei, ${ }^{1}$ Hong Zhu, ${ }^{3}$ and Xinyue $\mathrm{Zhou}^{4}$ \\ ${ }^{1}$ Department of Psychology, Sun Yat-Sen University, Guangzhou, China \\ 2 Department of Psychology, Ningbo University, Ningbo, China \\ ${ }^{3}$ School of Business, Nanjing University, Nanjing, China \\ ${ }^{4}$ School of Management, Zhejiang University, Hangzhou, China
}

\begin{abstract}
$\mathrm{T}$ his research examined whether feeling awe weakens people's desire for money. Two experiments demonstrated that, as a self-transcendent emotion, awe decreased people's money desire. In Experiment 1, recalling a personal experience of awe makes people place less importance on money, compared with recalling an experience of happiness and recalling a neutral experience. In experiment 2, we examined different variants of awe, such as negative awe and non-nature awe. Viewing images that elicited awe, no matter what kind of awe, can induce people to put less effort into obtaining money. Process evidence suggested that awe's weakening of money desire was due to its power to make people transcend their mundane concerns. Our findings have implications for willingness to donate, price sensitivity, religious practices, and economic utilities.
\end{abstract}

Keywords: awe, self-transcendence, money desire

When people witness something grand, sublime, or extremely powerful, they are struck with awe. The experience of awe gives people a sense of perspective on their life and makes them see the world in a new light (Bonner \& Friedman, 2011; Schneider, 2009). Indeed, awe releases people from their mundane concerns and enables them to transcend their day-to-day needs. For this reason, awe promotes religious and spiritual transformation (James, 1902/1922; Lazarus \& Lazarus, 1994). The present study builds on previous theories and researches on the spiritual nature of awe, asking whether awe helps suppress people's desire for money.

For people in a modern society, desire for money is one of the strongest motivations in their daily lives (Xie, Yu, Zhou, Sedikides, \& Vohs, 2014; Yang et al., 2013; Zhou, Feng, He, \& Gao, 2008; Zhou, Vohs, \& Baumeister, 2009). Money desire dominates many other desires in any human societies that use money (Lea \& Webley, 2006; Zhou \& Gao, 2008). Money is often valued to a great extent, much more than the value of the goods and services it can procure (Lea \& Webley, 2006; Zhou \& Gao, 2008). Previous research suggest that the experience of some emotions can suppress the desire for money (Lasaleta, Sedikides, \& Vohs, 2014). We propose that awe as a spiritual emotion can weaken the desire for money. We tested the hypothesis that feeling awe reduces desire for money, defined as the desire to acquire and hold onto money. The current study provides experimental evidence that documents the conflict between spiritual pursuits and monetary pursuits, which to date have largely been the subject of philosophical and theoretical speculation.

\section{Awe as a Transcendental Experience}

Awe as a spiritual emotion has long been the subject of philosophical and religious inquiry (e.g., Burke, 1990; Kant, 1790/1914). It is an emotion that has been associated with aesthetic response, political change, and religious transformation (Bonner \& Friedman, 2011; Burke, 1990; Keltner \& Haidt, 2003; Weber, 1947). In psychology, William James (1902/1922) and his contemporaries focused on its role in religious and spiritual transformation (Hall, 1897; Leuba, 1906; McDougall, 1908). Later, Keltner and Haidt (2003) proposed a theoretical framework to explain awe in terms of two features: perceptual vastness and need for accommodation. Vastness refers to unusually large stimuli. The awe-triggering stimuli can be enormous, physically or conceptually. The second feature of awe is the need for accommodation; that is, awe changes people's view of the world (Keltner \& Haidt, 2003). Specifically, awe stimulates a need for mental reorganisation to incorporate new experiences. During the experience of awe, people's current mental frameworks are challenged by the perceived vastness, which in turn foster (religious) belief adoption and/or ideological transformation.

This research was supported by the National Natural Science Foundation of China (71672169 \& 71372034).

Address for correspondence: Xinyue Zhou, School of Management, Zhejiang University, 866 Yuhangtang Road, Hangzhou, 310058, China. Email: xinyuezhou@zju.edu.cn 
Recently, researchers have taken an interest in uncovering downstream effects of awe. Not surprisingly, the experience of awe has been shown to make people endorse spiritual beliefs (Saroglou, Buxant, \& Tilquin, 2008; Van Cappellen \& Saroglou, 2012), attribute agency to random events (Valdesolo \& Graham, 2014), perceive more time available (Rudd, Vohs, \& Aaker, 2012), feel oneness with the external world (Shiota, Keltner, \& Mossman, 2007), behave cooperatively (Joye \& Bolderdijk, 2015; Piff, Dietze, Feinberg, Stancato, \& Keltner, 2015; Prade \& Saroglou, 2016), and increase prosocial behavior and collective engagement (Bai et al., 2017; Piff et al., 2015). This line of research points to the self-diminishing nature of awe. That is, awe diminishes individuals' concerns for themselves.

The experience of awe is often depicted as an experience of self-transcendence in which people transcend their daily concerns and mundane desires. The transcendental nature of awe may allow people to be free of their worldly desires. Self-transcendence is defined as the expanded boundaries of self (Reed, 1989, 1991). Feeling awe allows people to view themselves as part of something larger and to be as one with their surrounding world (Friedman, 1983; Pappas \& Friedman, 2007). The typical wonderment and fascination in the experience of awe leads people to consider themselves as less separate and more interrelated to the larger context of existence (Haidt, 2003; Halstead \& Halstead, 2004). Indeed, participants primed to recall a past experience of awe typically reported diminished self or small self, in which they feel small, insignificant, and a sense of shifting their attention away from personal day-to-day concerns (Bai et al., 2017; Piff et al., 2015; Shiota et al., 2007). It is probably because in the experience of awe, people are so absorbed in their fascination with the external stimulus that individual desires are put in a secondary place (Prade \& Saroglou, 2016). Like awe, self-transcendence diminishes personal concerns and selfinterest. Given the consideration that money functions as a critical medium to fulfill personal needs, it is therefore proposed that awe weakens the desire for money.

\section{Conflict Between the Spirit and the Flesh}

The hypothesis that awe reduces money desire is also supported by the conflict between the spirit and the flesh. Awe is a spiritual emotion. Since early days, awe was theorised by many to facilitate spiritual transformation and religious conversion (Haidt, 2006; Haidt \& Keltner, 2004; James, 1902/1922; Lazarus \& Lazarus, 1994). The experience of awe enables people to reassess their goals and desires and provide new perspectives about one's purpose and meaning (Bonner \& Friedman, 2011; Konecni, 2005; Lowenstein, 1999; McDonald, Wearing, \& Ponting, 2009; Pomfret, 2006; Schneider, 2009). Feeling awe drives people to consider deeper questions and open their minds to what the universe has to offer (Danvers \& Shiota, 2017). The power of awe in religious transformation is well illustrated in the story of Paul's conversion on the road to Damascus, as told in the Bible (Acts 9: 1-19). Awe transforms people and enables them to embrace new values and new beliefs.

Empirical evidence also supports awe as a spiritual emotion (Joye \& Verpooten, 2013). For example, an ethnographic study reveals that experiencing awe and wonderment after watching wildlife sparks spiritual feelings in tourists (Curtin, 2009). Moreover, experimental studies showed that priming awe increased participants' willingness to visit a spiritual destination (e.g., Tibet; Van Cappellen \& Saroglou, 2012). The experience of awe also increases belief in a supernatural agent (Valdesolo \& Graham, 2014); in particular, among spiritual people (Van Cappellen \& Saroglou, 2012).

As a spiritual emotion, awe may suppress the physical desire for money. The main function of money is to satisfy physical goals and needs. The conflict between awe and money can be driven by the conflict between the spirit and the flesh. Many religious writings have suggested the conflict between the spirit and the flesh (Galatians 5: 13-21; Grouzet et al., 2005). Philosophers such as William James (1892/1985) had long proposed the distinction between 'bodily me' and 'spiritual me'. Similarly, Freud (1960) emphasised the conflict between the 'id' and the 'superego'. Empirical studies on people's goals and values also suggest that activating the goal of spiritual pursuit may suppress the pursuit for bodily safety and hedonic pleasure (Grouzet et al., 2005). If the experience of awe drives people to transcend themselves and take on a spiritual quest, it then has the potential to inhibit the physical goals like the desire for money.

\section{The Present Research}

Two experiments tested the hypothesis that awe makes people desire money less than their neutral counterparts. We predicted that awe, relative to neutral affect, diminishes the value of money and that participants primed with awe are less willing to exert effort to obtain money. In addition, we predicted that the relation between awe and weakened money desire would be mediated by self-transcendence.

\section{EXPERIMENT 1}

The first objective of this experiment was to examine whether experiencing awe reduced the importance participants placed on money. In order to manipulate awe and control states in our participants, we used a well-validated priming technique to induce emotions by asking participants to recall and vividly relive a specific memory (e.g., Griskevicius, Shiota, \& Neufeld, 2010; Piff et al., 2015; Piff, Martinez, \& Keltner, 2012).

The second objective was to differentiate feelings of awe from general positive emotions. Thus, we included two control conditions (happy, neutral affect) along with the awe condition. Previous researches typically consider awe as a positive emotion (Fredrickson, 2001); including happiness as a control emotion allowed us to differentiate 
the effects of awe from the effects of happiness and test for the unique effect of awe.

Moreover, the third objective of experiment 1 was to explore the underlying mechanism of the central effect. If feeling awe indeed reduced the importance of money, is it because awe inspired people to transcend themselves from mundane concerns? We included a measure of selftranscendence to see whether feeling awe indeed influenced self-transcendence, which in turn reduced money importance.

\section{Method}

\section{Participants}

There were 208 Chinese participants who lived in Hangzhou, China, and they completed the study in exchange for a small monetary payment. Mean age of the sample was 22.38 ( $S D=3.84 ; 85$ males; 122 females; 1 unreported). Participants were randomly assigned to one of the three conditions.

\section{Materials and Procedure}

All investigations were conducted with questionnaires, and participants were asked to read texts or pictures on the questionnaires carefully and complete the corresponding questions. Specifically, after giving their consent, participants were asked to recall and write about an experience in which they felt the target emotion. We asked participants to recall a travel experience in order to make the experience more standard across conditions. Participants read instructions as below (adapted from Piff et al., 2015).

Awe: 'Please think about a travel experience, when you encounter something that caused you to feel awe. This might have been a glorious sunset or a magnificent landscape.'

Happy: 'Please think about a travel experience, when you felt happy. This might have been seeing something you like or having a nice time with friends.'

Neutral: 'Please think about a travel experience that happened fairly recently. This might have been riding a bike or any other thing that happened during that day.'

All participants wrote down sentences describing the experience in as much detail as possible. Following this, participants completed a seven-item scale (Lasaleta et al., 2014). In particular, participants rated the level of their agreement with these items: 'Money is important to me,' 'There is more to life than money (reverse coded),' 'People who chase money often chase away happiness (reverse coded),' 'The best things in life are free (reverse coded),' 'Frankly speaking, having money is something that I value,' 'To get the most of life, people need money,' and 'Frankly speaking, having money isn't all that important to me(reverse coded)' on a 7-point scale ( $1=$ strongly disagree; 7 = strongly agree; $\alpha=.82$ ).

Then, participants were presented with a measure of self-transcendence, including four items selected and adapted from The Self-Transcendence Scale (STS; Reed, $1989,1991)$. These four items $(\alpha=.74)$ were 'I want to find meaning in my experience,' 'I want to find answers to some universal spiritual questions,' 'I want to make sense of the world,' and 'I can move beyond things that once seemed so important'.

Finally, as the manipulation check, participants rated the degree to which they felt seven different emotions: anger, awe, disgust, fear, amusement, sadness, and happiness $(1=$ not at all, $7=$ extremely $)$, as in previous studies (e.g., Piff et al., 2015; Valdesolo \& Graham, 2014). Participants then reported their age and gender.

\section{Results}

\section{Manipulation Check}

Participants rated how much they felt anger, awe, disgust, fear, amusement, sadness, and happiness. As the above rated seven emotions may be correlated with each other to further examine whether the independent variable (i.e., emotion manipulation) differentially predicted the dependent variables (i.e., anger, awe, disgust, fear, amusement, sadness, and happiness), a multivariate analysis of variance (MANOVA) was conducted. It showed that groups differed in terms of awe, $F(2,205)=4.48, p=.013, \eta_{p}^{2}=$ .042 , happiness, $F(2,205)=6.82, p=.001, \eta_{p}^{2}=.062$, and amusement, $F(2,205)=7.53, p=.001, \eta_{p}^{2}=.068$. The awe group $(M=3.64, S D=1.86)$ felt more awe than the happy $(M=2.96, S D=1.91)$ and neutral conditions $(M=$ $2.71, S D=1.94$; awe vs. happy: $95 \%$ CI for mean difference [.05, 1.33], $p=.035$; awe vs. neutral: $95 \%$ CI for mean difference $[.29,1.56], p=.004)$. This result supports the success of our manipulation of the target emotion. Furthermore, the happy group felt happier than the awe and neutral groups $\left(M_{\text {awe }}=2.91, S D=1.60 ; M_{\text {happy }}=\right.$ $3.68, S D=1.51 ; M_{\text {neutral }}=2.71, S D=1.72$; happy vs. awe: $95 \% \mathrm{CI}$ for mean difference [.22, 1.30], $p=.006$; happy vs. neutral: $95 \% \mathrm{CI}$ for mean difference [.42, 1.50], $p=$ $.001)$. The happy group also felt more amused than the other two groups: $M_{\text {awe }}=2.74, S D=1.72 ; M_{\text {happy }}=3.41$, $S D=1.69 ; M_{\text {neutral }}=2.36, S D=1.43$; happy versus awe: $95 \%$ CI for mean difference [.13, 1.21], $p=.016$; happy versus neutral: $95 \% \mathrm{CI}$ for mean difference $[.51,1.60], p<$ .001. In terms of all the other emotions like anger, disgust, sadness, or fear, three groups did not differ significantly across conditions $\left(p s>.65, \eta_{p}^{2}<.005\right)$.

These results showed that we successfully manipulated our target emotion but did not influence the irrelevant emotions.

\section{The Effect of Awe on Money Importance}

A one-way ANOVA showed significant main effect for emotion manipulations on money importance, $F(2,205)=8.74, p<.001, \eta_{p}^{2}=.079$. Subsequent pairwise contrasts (see Figure 1) showed that the awe group $(M=2.80, S D=0.89)$ placed lower importance on money than the happy group $(M=3.59, S D=1.15)$ and the 


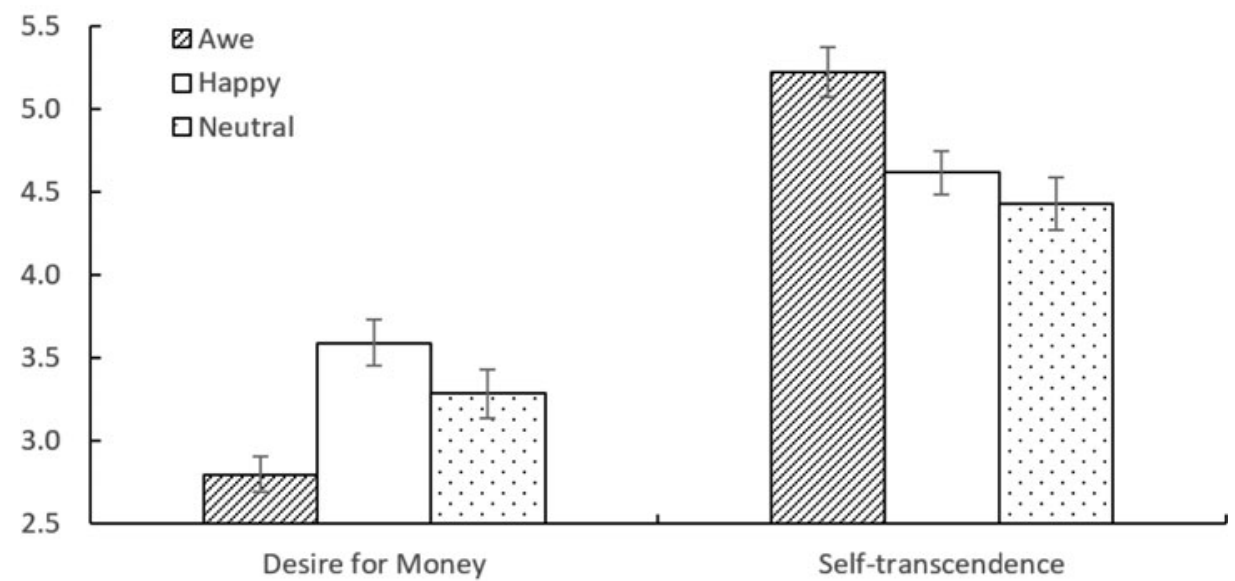

Figure 1

Study 1: Desire for money and self-transcendence.

neutral group $(M=3.28, S D=1.30$; awe vs. happy: $95 \%$ CI for mean difference $[-1.17,-.42], p<.001$; awe vs. neutral: $95 \% \mathrm{CI}$ for mean difference $[-.86,-.11], p=$ .011 ), whereas the difference between the happy group and the control group was not significant $\left(M_{\text {happy }}=3.59\right.$, $S D=1.15 ; M_{\text {neutral }}=3.28, S D=1.30 ; 95 \%$ CI for mean difference $[-.07, .68], p=.111)$. As expected, feeling awe reduced the desire for money, but feeling happy did not influence the desire for money.

\section{The Effect of Awe on Self-Transcendence}

With the composite score of self-transcendence as the dependent variable, a one-way ANOVA showed a significant main effect for emotion manipulations, $F(2,205)=8.17$, $p<.001, \eta_{p}^{2}=.074$. Pairwise contrasts showed that the awe group $(M=5.23, S D=1.24)$ reported more selftranscendence than the happy group $(M=4.62, S D=$ $1.04)$ and the neutral group $(M=4.43, S D=1.34$; awe vs. happy: $95 \%$ CI for mean difference [.20, 1.01], $p=.004$; awe vs. neutral: $95 \%$ CI for mean difference $[.39,1.20]$, $p<.001)$. The happy group and the neutral group did not differ significantly from each other $(95 \%$ CI for mean difference $[-.22, .59], p=.270)$.

\section{The Mediation Effect of Self-Transcendence}

As reported above, feeling awe reduced desire for money. But is this because of self-transcendence? Desire for money correlated negatively with self-transcendence, $r=-.32$, $p<.001$. Thus, we performed a mediation analysis to test whether recalling an awe experience reduced money desire via self-transcendence. Figure 2 illustrates the mediation model and provides path coefficients. As shown, the positive association between the awe induction (in contrast to the happy and neutral inductions) and money desire decreased when self-transcendence was included in the model. We tested the proposed mediating effect using a bootstrapping procedure for mediator models, recommended by Preacher and Hayes $(2004,2008)$. We con- ducted this analysis with the PROCESS macro for SPSS (Hayes, 2013) using 10,000 bootstrap samples. This technique yielded a 95\% bias-corrected confidence interval that did not include zero $(-.12$ to -.02$)$, suggesting that the self-transcendence mediated the effect of the awe induction on the desire for money.

\section{Discussion}

Experiment 1 demonstrated that participants who recalled an experience of awe tended to place less importance on money compared with those who recalled a happy experience or a neutral experience. This finding was consistent with our hypothesis. Moreover, experiment 1 also established specificity of the effect - namely that awe reduced desire for money, but not other positive emotions like happiness. Finally, experiment 1 also provided meditational results to show the underlying mechanism of the central effect, that the effect of awe on reduced money desire was mediated by self-transcendence. Experiencing awe reduced desire for money because awe induced people to transcend themselves to be more spiritual. This meditational result further bolstered confidence in our hypotheses.

\section{EXPERIMENT 2}

The results of experiment 1 showed that, relative to happy or neutral emotional states, awe reduces desire for money via self-transcendence. The purpose of experiment 2 was twofold. First, we needed to examine the generalisability of our effects by including two variants of awe inductions, a negative induction and a non-nature induction of awe. Although awe experiences are typically described as a positive emotion (Shiota et al., 2007), awe experiences can be negative because negative events such as natural disasters and extreme weather conditions may elicit awe heavily blended with fear (Keltner \& Haidt, 2003). In experiment 2, we induced this negative awe with a range of pictures depicting various natural disasters (i.e., 


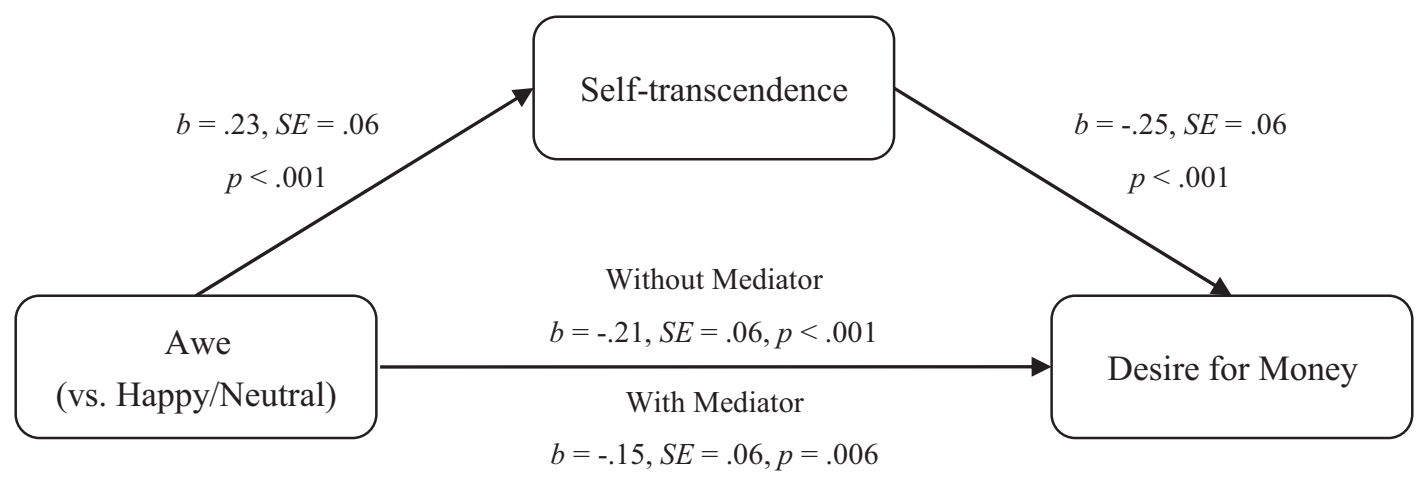

\section{Figure 2}

Study 1: Mediation via self-transcendence on desire for money.

Note: Mediation analysis with 10,000 bootstrap samples (model 4 in PROCESS; Hayes 2013). The predictor variable contrasts the awe condition against the happy and neutral conditions (awe $=2$, happy $=-1$, neutral $=-1$ ).

tornadoes, volcanoes, lightning strikes, and tsunamis) that had been adopted by previous studies and were proven to be successful (Danvers \& Shiota, 2017). Moreover, another variant of awe experience was also examined, which was non-nature awe. When participants recalled an experience of awe on their own, they typically experience an interaction with nature, while the percentage in such recalled contents did not differ from that of neutral condition (both around 50\%). Nevertheless, we wanted to further make sure that our effect was not due to the priming of natural scenes. Therefore, we included a non-nature awe condition in which participants viewed a stack of pictures consisting of awe-inspiring figures and historical sites (e.g., pyramid, Great Wall, Napoleon, Gandhi).

\section{Method}

\section{Participants}

Participants were 180 students from a large public university in Hangzhou, China. They completed the survey in exchange for a small monetary payment. Mean age of the sample was 22.35 ( $S D=3.17 ; 82$ males, 96 females, 2 unreported). They were randomly assigned to one of the three conditions (negative awe, non-nature awe, and control).

\section{Procedure and Measures}

All tests were completed in the form of questionnaires, and participants were asked to read texts or pictures in the questionnaires carefully and answer the corresponding questions. After giving consent, participants looked at a series of nine photographs for three minutes. These photographs were chosen based on descriptions in a previous research (Piff et al., 2015). Participants in the negative awe condition viewed pictures depicting dangerous natural phenomena, including tornados and lightning strikes, tsunamis, and volcanoes. Participants in the non-nature awe condition looked at pictures depicting a pyramid, the Great Wall, Gandhi, and museum exhibits such as notes and diagrams of Da Vinci, whereas participants in the neutral condition looked at pictures depicting prosaic interior and exterior scenes, such as a bus stop, a desk, and a bedroom. After passive viewing, participants were asked to write down a description of all the pictures they had just viewed.

Participants were then informed that they could make money by listening to the unpleasant sound of nail scratching. The sound would last for five minutes. Participants would be paid $20 \mathrm{RMB}$ if they were willing to listen to the sound for five minutes. Participants indicated the extent to which they are willing to complete the task for money $(1=$ not at all $;=$ very much $)$.

Finally, participants filled out money-importance $(\alpha=$ $.82)$, self-transcendence $(\alpha=.84)$, and the manipulation check items with the same measures as in experiment 1. Then they reported their age and gender.

\section{Results}

\section{Manipulation Check}

For six emotion manipulation items, participants reported the extent (from $1=$ not at all to $7=$ extremely) to which they felt different emotional states using the single items of anger, awe, disgust, fear, amusement, sadness, and happiness. Similar to experiment 1 , to further examine whether the independent variable (i.e., emotion manipulation) differentially predicted the dependent variables (i.e., anger, awe, disgust, fear, amusement, sadness, and happiness), a MANOVA was conducted. It was shown that the three groups differed in terms of awe, $F(2,177)=4.75, p=.010$, $\eta_{p}^{2}=.051$, fear, $F(2,177)=6.38, p=.002, \eta_{p}^{2}=.067$, and sadness, $F(2,177)=5.35, p=.006, \eta_{p}^{2}=.057$. In terms of awe, two awe conditions $\left(M_{\text {negative }}=3.82, S D=2.24\right.$; $\left.M_{\text {non-nature }}=3.67, S D=1.77\right)$ reported greater level of awe than the neutral condition $(M=2.78, S D=1.91$; negative awe vs. neutral: $95 \%$ CI for mean difference [.32, 1.75], $p=.005$; non-nature awe vs. neutral: $95 \%$ CI for mean difference $[.17,1.60], p=.016)$. In terms of fear, the negative awe conditions produced greater level of fear $\left(M_{\text {negative }}\right.$ $=2.50, S D=1.79 ; M_{\text {non-nature }}=1.75, S D=1.30 ; M_{\text {neutral }}$ 
$=1.63, S D=1.16$; negative awe vs. non-nature awe: $95 \%$ CI for mean difference [.23, 1.27], $p=.005$; negative awe vs. neutral: $95 \%$ CI for mean difference $[.35,1.39], p=$ $.001)$ and sadness than the non-nature awe and the neutral conditions $\left(M_{\text {negative }}=2.43, S D=1.52 ; M_{\text {non-nature }}=\right.$ $1.77, S D=1.27 ; M_{\text {neutral }}=1.72, S D=1.21 ;$ negative awe vs. non-nature awe: $95 \%$ CI for mean difference [.18, 1.15], $p=.007$; negative awe vs. neutral: $95 \%$ CI for mean difference $=[.23,1.20], p=.004)$. The manipulation did not exert a significant effect on anger, disgust, amusement, and happiness ( $\left.p s>.10, \eta_{p}^{2}<.025\right)$. These findings verified that the emotion manipulations elicited the intended emotional states.

\section{The Effect of Awe on Money Importance}

A one-way ANOVA showed a significant main effect for emotion manipulations on money importance, $F(2,177)=4.45, p=.013, \eta_{p}^{2}=.048$. Subsequent pairwise contrasts showed that the negative awe group $(M=$ $2.84, S D=1.19)$ and the non-nature awe group $(M=2.95$, $S D=1.08)$ placed lower importance on money than the neutral group $(M=3.44, S D=1.24$; negative awe vs. neutral: $95 \%$ CI for mean difference $[-1.02,-.18], p=.006$; non-nature awe vs. neutral: 95\% CI for mean difference $[-.91,-.07], p=.024)$, whereas the difference between the negative awe group and the non-nature awe group was not significant $\left(M_{\text {negative }}=2.84, S D=1.19 ; M_{\text {non-nature }}=\right.$ $2.95, S D=1.08 ; 95 \% \mathrm{CI}$ for mean difference $[-.31, .53]$, $p=.602$ ). As expected, feeling awe reduced the desire for money.

\section{The Effect of Awe on Desire to Obtain Money}

Participants were asked to indicate their willingness to complete an unpleasant task to make money. With this index as the dependent variable, a one-way ANOVA showed a significant main effect for emotion manipulations, $F(2$, $177)=3.70, p=.027, \eta_{p}^{2}=.040$. Pairwise contrasts showed that the negative awe group $(M=4.12, S D=2.08)$ and the non-nature awe group $(M=4.25, S D=1.92)$ had lower willingness than the neutral group $(M=4.98, S D=$ 1.60; negative awe vs. neutral: $95 \%$ CI for mean difference $[-1.54,-.19], p=.012$; non-nature awe versus neutral: $95 \% \mathrm{CI}$ for mean difference $[-1.41,-.06], p=.034)$. The negative awe group and the non-nature awe group did not differ significantly from each other (95\% CI for mean difference $[-.54, .81], p=.698)$.

\section{The Effect of Awe on Self-Transcendence}

A one-way ANOVA with the composite score of selftranscendence as the dependent variable showed a significant main effect for emotion manipulations, $F(2,177)=$ $5.35, p=.006, \eta_{p}^{2}=.057$. Pairwise contrasts showed that the negative awe group $(M=5.12, S D=1.32)$ and the non-nature awe group $(M=5.14, S D=1.25)$ were more than the neutral group $(M=4.44, S D=1.44$; negative awe versus neutral: $95 \%$ CI for mean difference [.20, 1.17], $p=.006$; non-nature awe versus neutral: 95\% CI for mean difference $[.22,1.18], p=.005)$. And the negative awe group and the non-nature awe group did not differ significantly from each other (95\% CI for mean difference $[-.50, .47], p=.946)$.

\section{The Mediation Effect of Self-Transcendence}

As reported above, the awe manipulations decreased the willingness to complete an unpleasant task for money. Moreover, desire for money correlated negatively with self-transcendence, $r=-.35, p<.001$. Thus, we performed a mediation analysis to test whether the awe induction decreased money desire via self-transcendence. Figure 3 illustrates the mediation model and provides path coefficients. As shown, the negative association between the awe inductions (in contrast to the neutral induction) and money desire dropped to non-significant when selftranscendence was included in the model. We tested the proposed mediating effect using a bootstrapping procedure for mediator models recommended by Preacher and Hayes $(2004,2008)$. We conducted this analysis with the PROCESS macro for SPSS (Hayes, 2013) using 10,000 bootstrap samples. This technique yielded a 95\% biascorrected confidence interval that did not include zero $(-.20,-.04)$, suggesting that the self-transcendence mediated the effect of the awe induction on the desire for money.

\section{Discussion}

Experiment 2 contrasted different variants of awe and lends further support for our hypothesis that awe has unique effects on money desire. Even though the content of negative awe and non-nature awe differed from prototypical awe experiences, their effect on money desire converged to provide a consistent picture that awe reduced money desire.

Furthermore, experiment 2 showed that awed participants were less willing to endure an aversive sound in exchange for monetary reward, compared with neutral participants. In experiment 1 , money desire was assessed with a scale of money importance, whereas in experiment 2, we used a different operationalisation of money desire. As predicted, awe inductions reduced the desire to obtain money, and this effect was due to increased self-transcendence.

\section{General Discussion}

The current work tested the hypothesis that awe reduces the desire for money, a hypothesis based on previous theories regarding awe as a spiritual emotion. The literature strongly suggests that feeling awe induces spiritual and transcendent pursuits (Van Cappellen \& Saroglou, 2012). Our hypotheses are also consistent with the empirical studies showing that feeling awe makes people become more generous and more likely to donate money to help others (Piff et al., 2015). The present study also builds 


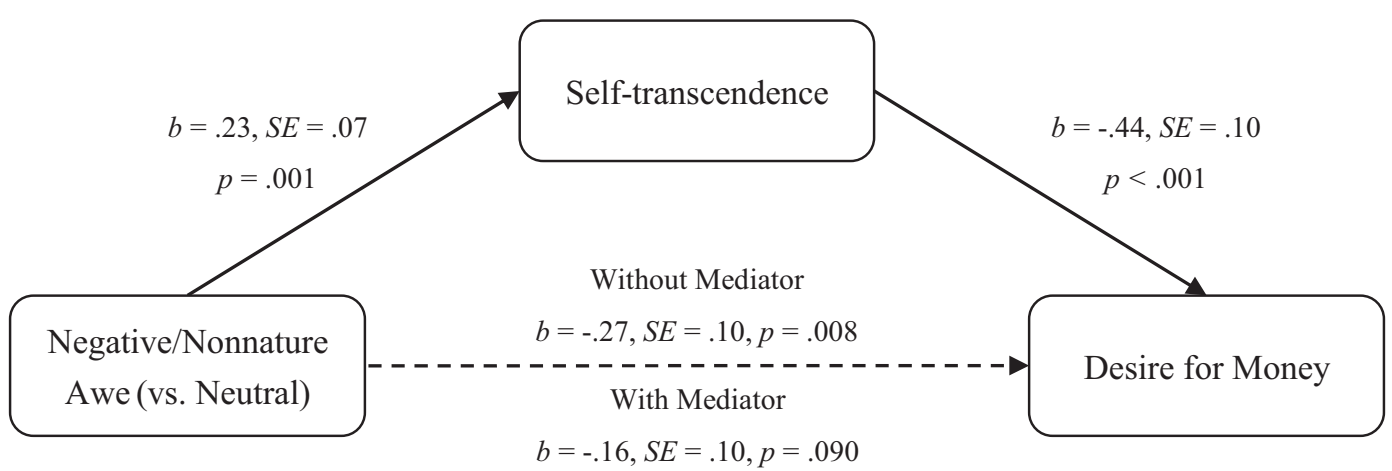

\section{Figure 3}

Study 2: Mediation via self-transcendence on desire for money.

Note: Mediation analysis with 10,000 bootstrap samples (model 4 in PROCESS; Hayes 2013). The predictor variable contrasts the two awe conditions against the neutral conditions (negative awe $=1$, non-nature awe $=1$, neutral $=-2$ ).

on previous researches that examined how the desire for money can be weakened or strengthened (Briers, Pandelaere, Dewitte, \& Warlop, 2006; Lasaleta et al., 2014).

The results of the two experiments supported the hypothesis. We manipulated awe through a recall task (experiment 1) or a picture viewing task (experiment 2). Money desire was measured by an attitudinal survey (experiment 1) or an indicated willingness to obtain money (experiment 2). Furthermore, we collected process evidence using a validated scale of self-transcendence. These varied procedural changes were implemented to gather evidence of robustness and convergence.

Furthermore, we compared awe induction with happiness and neutral states in experiment 1 . The effect of awe can be differentiated not only from a neutral emotional state, but also from a positive emotional state. And in experiment 2, we included two variants of awe inductions, negative awe and non-nature awe. These manipulations were adopted to ascertain the specificity of the effect. The effect of awe on money desire remained the same across different variants of awe and different manipulations of awe. Our findings also addressed an alternative explanation that feeling awe weakens desire for money because it is a positive emotion, as we included happiness as a typical positive emotion in experiment 1 and did not find the same effect for happiness. Moreover, given that in experiment 1 awe and happiness conditions recalled the contents about the nature experience and the social event respectively, it is possible that the reduced desire for money from the awe state would be due to the different contexts (nature vs. social) rather than emotional states (awe vs. happiness). If only the awe condition was compared with the happiness condition in experiment 1 , the above explanation would be possible, but a neutral context was also included in experiment 1 , in which participants were asked to recall a normal travel experience. This condition was also dominated by nature content instead of social experiences, but produced no different effects on money, relative to the happiness condition. Furthermore, experiment 2 provided additional evidence that awe reduced money desire, by comparing the nature awe and the non-nature awe. Hence, by integrating all findings, it is likely that the specific content in awe reduces the desire for money.

Feeling awe in the face of the vastness of the world allows people to transcend themselves. Recalling a past experience of awe shifted people's attention from themselves to focus on something greater than themselves (Shiota et al., 2007). It is probably because people in awe are so absorbed by their fascination with the external stimulus that the physical self is put in a secondary place (Prade \& Saroglou, 2016). People in awe start to appreciate their sense of selfhood as less separate and more interrelated to the larger existence (Haidt, 2003; Halstead \& Halstead, 2004). The experience of awe elevates people from their mundane concerns, which are bounded by daily experiences such as the desire for money. Previous research has showed that the de-emphasis on one's self can lead people to give more money to others (Piff et al., 2015). Consistent with this line of research, we show that feeling awe allows people to transcend themselves and their personal needs, which in turn leads to reduced desire for money.

The current study raises a question about how specific the awe effect on money is, as the awe is suggested to be correlated with the emotion of admiration (Aaker, Garbinsky, \& Vohs, 2012; Rudd, Vohs, \& Aaker, 2012). Admiration is described as 'surprise associated with some pleasure and a sense of approval', and followers feeling admiration have a desire for proximity towards the source inducing this emotion (i.e., prestigious people), with a self-improvement motivation (Algoe \& Haidt, 2009). However, the selfimprovement motivation does not ensure that its contents are about a purely spiritual pursuit; for example, the admiration of wealthy persons may make followers pursue money. Yet, admiration is mainly deemed to be a positive emotion, while humans also express their awe of a negative disaster, as the current studies have suggested. Aaker and colleagues (2012) have suggested that the feelings about 
the positive endpoint of admiration should be placed in another way - namely, as feelings of awe. Furthermore, from a functional perspective, the feeling of admiration directs a follower to enhance their competence or knowledge of the admired source, but the feeling of awe motivates an actor to reconstruct their knowledge and sometimes lets the actor keep a distance from the source. Hence, we speculate that awe and admiration should be considered as two distinct emotions, at least for the function of spiritual pursuit. Possibly, awe has unique effects on desire for money that are at least more effective than admiration in motivating spiritual pursuit. Such speculation needs further addressing.

In most cases, people satisfy their needs in two ways of social interaction: constructing close communal ties and dealing with others in a marketplace, accordingly shaping two types of relationships: communal relationship and exchange relationship (Clark \& Mills, 2012; Gasiorowska, Chaplin, Zaleskiewicz, Wygrab, \& Vohs, 2016). In the mode of communal relationship, people treat all members of a category as equivalent and are concerned about other's needs and are altruistic to people of their own kind. In contrast, in exchange relationships, people care more about cost-benefit assessment and give benefits with the expectation of receiving comparable benefits in return. Possibly, awe could prime participants' communal relationship mode, as awe-filled contexts can make observers' selves feel smaller, and accordingly motivate them to become more interrelated and inseparable from the larger group. This enhanced need to form communal relationships would thereby inhibit the exchange relationship mode, which is suggested to be instantiated in the symbol of money (Sandel, 2012); accordingly, the reduced desired for money due to the awe would be observed. It would interesting to address this issue in the future.

Since Keltner and Haidt's theoretical article on awe (2003), a small research literature has begun to accrue examining some downstream effects of awe. Following the present work, future studies could explore other physical desires as possible downstream consequences of awe. For example, does feeling awe reduce the desire for food? Desire for food is central to survival and is considered to be a means of preventing the body's energy resources from falling to low levels. Previous research suggests that desire for money is a modern derivate of their desire for food (Briers et al., 2006). Exploring this line of research would provide insight into many religious practices that forbid people to eat for a certain period of time or forbid certain types of food. It seems that depriving people of food can drive them to become more spiritual and religious. Future research could explore the possibility that feeling awe can reduce the desire for food and whether deprivation of food can make people more likely to feel awe.

Our findings shed light on why people are willing to make great sacrifices for their religion. The idea that an emotion that is central to religion can reduce people's desire for money has important implications for economics, which assumes that the marginal utility of money depends on what money can buy. Our findings may help explain why people are willing to donate all their money to religion. In cultures like Tibet, believers are willing to donate their last cent to their temple (Carrasco, 1959; Geoffrey, 1993). Our findings thus have implications for willingness to donate, price sensitivity, religious practices, and economic utilities.

\section{References}

Aaker, J.L., Garbinsky, E.N., \& Vohs, K.D. (2012). Cultivating admiration in brands: Warmth, competence, and landing in the 'golden quadrant'. Journal of Consumer Psychology, 22, 191-194.

Algoe, S.B., \& Haidt, J. (2009). Witnessing excellence in action: The 'other-praising' emotions of elevation, gratitude, and admiration. The Journal of Positive Psychology, 4, 105-127.

Bai, Y., Maruskin, L.A., Chen, S., Gordon, A.M., Stellar, J.E., McNeil, G.D., ... Keltner, D. (2017). Awe, the diminished self, and collective engagement: Universals and cultural variations in the small self. Journal of Personality and Social Psychology, $113,185-209$.

Bonner, E.T., \& Friedman, H.L. (2011). A conceptual clarification of the experience of awe: An interpretative phenomenological analysis. The Humanistic Psychologist, 39, 222-235.

Briers, B., Pandelaere, M., Dewitte, S., \& Warlop, L. (2006). Hungry for money: The desire for caloric resources increases the desire for financial resources and vice versa. Psychological Science, 17, 939-943.

Burke, E. (1990). A philosophical inquiry into the origin of our ideas of the sublime and beautiful. Oxford, UK: Oxford University Press.

Carrasco, P. (1959). Land and polity in Tibet. Seattle, WA: University of Washington Press.

Clark, M.S., \& Mills, J.R. (2012). A theory of communal (and exchange) relationships. In P.A.M. Van Lange, A.W. Kruglanski, \& E.T. Higgins (Eds.), Handbook of theories of social psychology (pp. 232-250). Thousand Oaks, CA: Sage Publications.

Curtin, S. (2009). Wildlife tourism: The intangible, psychological benefits of human-wildlife encounters. Current Issues in Tourism, 12, 451-474.

Danvers, A.F., \& Shiota, M.N. (2017). Going off script: Effects of awe on memory for script-typical and -irrelevant narrative detail. Emotion, 17, 938-952.

Freud, S. (1960). The ego and the id. New York, NY: W.W. Norton.

Fridrickson, B.L. (2001). The role of positive emotion in positive psychology: The broaden-and-build theory of positive emotions. American Psychologist, 56, 218-226.

Friedman, H.L. (1983). The self-expansive level form: A conceptualization and measurement of a transpersonal construct. The Journal of Transpersonal Psychology, 15, 37-50.

Gasiorowska, A., Chaplin, L.N., Zaleskiewicz, T., Wygrab, S., \& Vohs, K.D. (2016). Money cues increase agency and decrease prosociality among children: Early signs of market-mode behaviors. Psychological Science, 27, 331-344. 
Geoffrey, S. (1993). Civilized shamans: Buddhism in Tibetan societies. Washington, DC: Smithsonian Institution Press.

Griskevicius, V., Shiota, M.N., \& Neufeld, S.L. (2010). Influence of different positive emotions on persuasion processing: a functional evolutionary approach. Emotion, 10, 190206.

Grouzet, F.M., Kasser, T., Ahuvia, A., Dols, J.M.F., Kim, Y., Lau, S., ... Sheldon, K.M. (2005). The structure of goal contents across 15 cultures. Journal of Personality and Social Psychology, 89, 800-816.

Haidt, J. (2003). The moral emotions. In R.J. Davidson, K.R. Scherer, \& H.H. Goldsmith (Eds.), Handbook of affective sciences (pp. 852-870). Oxford, UK: Oxford University Press.

Haidt, J. (2006). The happiness hypothesis: Finding modern truth in ancient wisdom. New York: Basic Books.

Haidt, J., \& Keltner, D. (2004). Appreciation of beauty and excellence. In C. Peterson \& M.E.P. Seligman (Eds.), Character strengths and virtues (pp. 537-551). Washington, DC: American Psychological Association Press.

Hall, G.S. (1897). A study of fears. The American Journal of Psychology, 8(2), 147-249.

Halstead, J.M., \& Halstead, A.O. (2004). Awe, tragedy and the human condition. International Journal of Children's Spirituality, 9, 163-175.

Hayes, A.F. (2013). Introduction to mediation, moderation, and conditional process analysis: A regression-based approach. New York, NY: Guilford Press.

James, W. (1892/1985). Psychology: The briefer course. Notre Dame, IN: University of Notre Dame.

James, W. (1902/1922). The varieties of religious experience: A study in human nature. London: Longmans, Green and Co.

Joye, Y., \& Bolderdijk, J. (2015). An exploratory study into the effects of extraordinary nature on emotions, mood, and prosociality. Frontiers in Psychology, 5, 1577.

Joye, Y., \& Verpooten, J. (2013). An exploration of the functions of religious monumental architecture from a Darwinian perspective. Review of General Psychology, 17, 53-68.

Kant, I. (1790/1914). Kant's critique of judgement. New York: Macmillan.

Keltner, D., \& Haidt, J. (2003). Approaching awe, a moral, spiritual, and aesthetic emotion. Cognition and Emotion, 17, 297314 .

Konecni, V.J. (2005). The aesthetic trinity: Awe, being moved, thrills. Bulletin of Psychology and the Arts, 5, 27-44.

Lasaleta, J.D., Sedikides, C., \& Vohs, K.D. (2014). Nostalgia weakens the desire for money. Journal of Consumer Research, 41, 713-729.

Lazarus, R.S., \& Lazarus, B.N. (1994). Passion and reason: Making sense of our emotions. New York: Oxford University Press.

Lea, S.E., \& Webley, P. (2006). Money as tool, money as drug: The biological psychology of a strong incentive. Behavioral and Brain Sciences, 29, 161-209.

Leuba, J.H. (1906). Fear, awe and the sublime in religion: A chapter in the study of instincts, impulses, and motives in religious life. American Journal of Religious Psychology and Education, 2, 1-23.

Loewenstein, G. (1999). Because it is there: The challenge of mountaineering ... for utility theory. Kyklos, 52, 315-343.

McDonald, M.G., Wearing, S., \& Ponting, J. (2009). The nature of peak experience in wilderness. The Humanistic Psychologist, 37, 370-385.

McDougall, W. (1908). An introduction to social psychology. London: Methuen.

Pappas, J.D., \& Friedman, H.L. (2007). The construct of selfexpansiveness and the validity of the Transpersonal Scale of the Self-expansiveness Level Form. The Humanistic Psychologist, 35, 323-347.

Piff, P.K., Dietze, P., Feinberg, M., Stancato, D.M., \& Keltner, D. (2015). Awe, the small self, and prosocial behavior. Journal of Personality and Social Psychology, 108, 883-899.

Piff, P.K., Martinez, A.G., \& Keltner, D. (2012). Me against we: In-group transgression, collective shame, and in-groupdirected hostility. Cognition and Emotion, 26, 634-649.

Pomfret, G. (2006). Mountaineering adventure tourists: A conceptual framework for research. Tourism Management, 27, 113-123.

Prade, C., \& Saroglou, V. (2016). Awe's effects on generosity and helping. The Journal of Positive Psychology, 11, 522-530.

Preacher, K.J., \& Hayes, A.F. (2004). SPSS and SAS procedures for estimating indirect effects in simple mediation models. Behavior Research Methods, 36, 717-731.

Preacher, K.J., \& Hayes, A.F. (2008). Asymptotic and resampling strategies for assessing and comparing indirect effects in multiple mediator models. Behavior Research Methods, 40, 879-891.

Reed, P.G. (1989). Mental health of older adults. Western Journal of Nursing Research, 11, 143-163.

Reed, P.G. (1991). Self-transcendence and mental health in oldest-old adults. Nursing Research, 40, 5-11.

Rudd, M., Vohs, K.D., \& Aaker, J. (2012). Awe expands people's perception of time, alters decision making, and enhances well-being. Psychological Science, 23, 1130-1136.

Sandel, M.J. (2012). What money can't buy: The moral limits of markets. New York: Farrar, Straus and Giroux.

Saroglou, V., Buxant, C., \& Tilquin, J. (2008). Positive emotions as leading to religion and spirituality. The Journal of Positive Psychology, 3, 165-173.

Schneider, K.J. (2009). Awakening to awe: Personal stories of profound transformation. Lanham, MD: Jason Aronson.

Shiota, M.N., Keltner, D., \& Mossman, A. (2007). The nature of awe: Elicitors, appraisals, and effects on self-concept. Cognition and Emotion, 21, 944-963.

Valdesolo, P., \& Graham, J. (2014). Awe, uncertainty, and agency detection. Psychological Science, 25, 170-178.

Van Cappellen, P., \& Saroglou, V. (2012). Awe activates religious and spiritual feelings and behavioral intentions. Psychology of Religion and Spirituality, 4, 223-236.

Weber, M. (1947). Economy and society: An outline of interpretive sociology. Berkeley, CA: University of California Press. 
Xie, W., Yu, B., Zhou, X., Sedikides, C., \& Vohs, K.D. (2014). Money, moral transgressions, and blame. Journal of Consumer Psychology, 24, 299-306.

Yang, Q., Wu, X., Zhou, X., Mead, N.L., Vohs, K.D., \& Baumeister, R.F. (2013). Diverging effects of clean versus dirty money on attitudes, values, and interpersonal behavior. Journal of Personality and Social Psychology, 104, 473-489.

Zhou, X., Feng, C., He, L., \& Gao, D.G. (2008). Toward an integrated understanding of love and money: Intrinsic and ex- trinsic pain management mechanisms. Psychological Inquiry, 19, 208-220.

Zhou, X., \& Gao, D.G. (2008). Social support and money as pain management mechanisms. Psychological Inquiry, 19, 127144.

Zhou, X., Vohs, K.D., \& Baumeister, R.F. (2009). The symbolic power of money: Reminders of money alter social distress and physical pain. Psychological Science, 20, 700706. 